\title{
Editorial
}

\section{Dialectics of the Current Regulatory and Supervisory Developments in Insurance}

\author{
Jan Monkiewicz ${ }^{\mathrm{a}, \mathrm{b}}$ \\ ${ }^{a}$ Warsaw Technical University, Narbutta 85, Warsaw 02-524, Poland. \\ Email: j.monkiewicz@onet.eu \\ ${ }^{\mathrm{b}}$ The Geneva Association, Route de Malagnou 53, CH - 1208 Geneva, Switzerland.
}

The Geneva Papers (2013) 38, 183-188. doi:10.1057/gpp.2013.8

Public regulation and supervision of insurance activities are the two most powerful instruments every jurisdiction has for market-shaping. Their role is to bring socially desired properties into the ways and means in which commercial institutions are operated. Until the 1980s, they had been centralised in the hands of one body, but now are becoming increasingly separated and delegated to different agencies within governmental structures.

Regulation, which is about standards-setting, is naturally closely tied to lawmaking and thus exposed to political and market pressures. By its very nature it is faced with the unavoidable danger of regulatory capture to the benefit of specific interest groups within the insurance industry, or outside of it to the benefit of competitors, customers, suppliers, etc. ${ }^{1}$

Supervision, in contrast to regulation, is only slightly involved in standards-setting activities, which, if they exist, generally take place at the grassroots level. Its main focus is the enforcement of regulatory requirements in practice, that is their implantation in the insurance institutions supervised or the market at large. Hence it is closer to the technical side of the business and focused more on the micro than the macro dimension. However, this classical feature of supervision has been challenged by the recent global financial crisis. As a result, microprudential supervision aside, a new macroprudential pillar is rapidly coming into existence. Because of its technical nature, supervision is less endangered by capture phenomena, which was one of the fundamental reasons for its separation from regulatory activities.

To ensure further supervisory objectivity and avoid its potential capture, it is increasingly recommended to separate its operation from all political, governmental and industry interference. ${ }^{2}$

In spite of these fundamental differences between regulation and supervision, in practice, they are like twin brothers; they depend on each other. Regulation without an enforcement mechanism is simply powerless. Supervision, on the other hand, for its operation, requires a legal framework provided mainly by regulation. Because it is in the forefront of the market and in daily contact with market institutions, supervision is

\footnotetext{
1 Posner (1974).

${ }^{2}$ IAIS (2012a).
} 
well positioned to provide important alert signals and inputs into the regulatory process. The better the professional quality of supervisory institutions, the better the chances of adequate regulatory focus and regulatory standards. Supervisory institutions at the same time set the limits of the regulatory framework, that is, they define the possible applicability or, perhaps, better feasibility of the standards to be met both by the entities supervised and by the supervisory system.

Since the end of the last century, regulation and supervision alike have been increasingly faced with the globalisation of insurance operations and of insurance entities. This creates mounting pressure for an internationally coordinated regulatory framework and transborder supervisory cooperation and consolidation. ${ }^{3}$ Recent EU decisions are an indication of the future directions that may be taken in this regard. However, here the insurance industry is still far behind the banking and securities sectors, but apparently accelerating. The recent International Association of Insurance Supervisors (IAIS) initiative "Common Assessment Framework for Internationally Active Insurance Groups" or "Comframe" and the strong political support it has received from the G20 are a clear reflection of this need. ${ }^{4}$

In the aftermath of the global financial crisis, we are faced with the increased regulatory penetration of the finance and insurance industry and the expansion of regulation culture. It is enough to mention the wave of recently introduced or debated standards on solvency, corporate governance, fit and proper internal controls, transparency, financial conglomerates, insurance groups, financial reporting, etc. In addition, regulatory standards have been expanded to include previously largely unregulated activities - intermediation, reinsurance and personal claims advisors. In addition, the role of self-regulation has been marginalised (a good example is FSA supervisory jurisdiction since 2002 over the previously self-regulatory independence of Lloyds.)

The global regulatory agenda continues to keep its momentum, though some signs of regulatory fatigue and requests for reconsideration of the overall regulatory approach are visible. In its last report on "Progress of Financial Regulatory Reforms", delivered on 31 October 2012 to G20 finance ministers and central bank governors, the FSB, while giving a generally positive assessment of the post-crisis accomplishments of the global regulatory community, at the same time draws attention to some important failures.

It stresses in particular the slow pace of Basel III implementation, with only eight out of the 27 member jurisdictions of the Basel Committee on time to start the transitional phase on 1 January 2013. This could mean inter alia that only six out of the 28 global systemically important banks may be subject to Basel III regulations on this date. It also denotes weak preparation on the part of the supervisory systems to ensure their effectiveness and a forward-looking orientation with regard to the SIFI framework. ${ }^{5}$ In addition, it points out the inadequate advance in limiting the reliance of market participants on credit rating agencies and their procyclical effects. Succinctly

\footnotetext{
${ }^{3}$ Brown (2009) and Avgouleas (2012).

${ }^{4}$ IAIS (2012b).

${ }^{5}$ Carney (2012).
} 
stated, it seems that the dominant tone of the FSB music is that more and quicker regulatory intervention is necessary. This view, luckily enough, is not unanimously shared, even in the global regulatory community itself. In his famous speech delivered at the Federal Reserve Bank of Kansas City's $36^{\text {th }}$ economic policy symposium in Jackson Hole, Wyoming in August 2012, Andrew Haldane, Executive Director of the Bank of England, called for radical simplification of financial regulation. He justified this on the grounds that the ever-growing penetration of financial regulation did not prevent the financial crisis from happening. As he pointed out, Basel I of 1988 was only 30 pages long, while Basel II in 2004 already reached 350 pages, and Basel III in 2010 over 600 pages. Within 20 years the size of the principal regulatory standard in banking increased twentyfold! ${ }^{6}$ The EU Solvency II Directive is moving apparently along the same road. The first set of insurance directives dealing with solvency back in the 1970s was 30 pages long; the current Solvency II draft framework is 155 pages long, and the proposed Omnibus amendment is over 50 pages long. With the implementing measures to come, Solvency II may well reach over 1,000 pages. This, of course, means immensely increasing compliance costs for the financial sector. For banks, the cost of compliance with new regulations will be considerable: according to McKinsey \& Company, Basel III will generate, for a midsize bank in the EU, over 200 full-time jobs, which translates into around 70,000 jobs in the banking sector altogether. ${ }^{6}$ For insurers, the 2010 survey by Accenture ${ }^{7}$ finds that more than three quarters of large European insurers expect to spend around 25 million euros each through 2012 on Solvency II compliance alone. At the same time, it is estimated by IT providers that the European insurance industry needs to spend $€ 700-900$ million for new IT projects to comply with Solvency II. Despite their complexity and costs, financial regulations are not delivering or bringing satisfactory results. For this reason, Andrew Haldane claims that we should reconsider the way they are setup generally and look for a different orientation. In financial regulation - according to Haldaneless may be more. It is a courageous and promising statement, particularly when formulated by a key representative of the global regulatory community.

Since the beginning of this century, public regulation and supervision have faced the ever-stronger competition and challenge of private credit rating agencies that not only prescribe prudential standards to financial institutions based on their own independently developed models and policies, but also check for compliance with the recommended standards by the insurance institutions assessed, thus influencing the behaviour of their debtors and shareholders. The market impact of these agencies' supervisory assessment is speedier and much more profound than that of public regulatory authorities. Therefore, for the large-listed insurance companies, they have become the primary driving force of applied prudential standards. They also increasingly influence the standards adopted later by public regulatory authorities.

In fulfilling its mission, The Geneva Association runs several research programmes, one of which is the programme on Regulation, Supervision and Legal Issues (PROGRES). The central focus of PROGRES is on global and major international

\footnotetext{
${ }^{6}$ Haldane (2012).

${ }^{7}$ Accenture (2010).
} 
regulatory and supervisory issues with special interest on the impact of approved or proposed standards and policies on the business space of the insurance industry. Since 1983, PROGRES has organised an annual forum and meeting point for the global regulatory and supervisory community called the PROGRES seminar. It brings together a select number of specialist participants including representatives of key global regulatory and supervisory authorities, officials from governments and relevant international organisations, scholars and private sector practitioners to discuss current challenges and policies in global insurance regulation and supervision.

An important part of the research and outreach activities of PROGRES are its publications and, in particular, special issues of The Geneva Papers on Risk and Insurance-Issues and Practice dedicated to its selected topics of interest. This issue brings together eight contributions from different countries focusing on selected, current regulatory and supervisory challenges reflecting some of the dilemmas we mentioned earlier. Special attention is given to the most prominent and demanding regulatory and supervisory project in insurance, that is Solvency II. This topic is addressed by half of the collected papers, which may be taken as the reflection of the interest and importance assigned by the research community to this venture and its implications for the insurance industry at large. The remaining papers deal with other relevant topics.

In the first contribution, Alberto Floreani provides an interesting analysis of Solvency II value at risk (VAR)-based capital. He defends the point of view that, contrary to expectations, the new regulatory framework will increase the fragility of the insurance industry compared to the existing solvency system. This happens because the new Directive endorses the use of a wrong risk measure, that is VAR. According to Floreani, VAR exposes insurance companies to a potentially huge systemic risk, as it represents a total risk measure of both systematic and diversifiable risks. In effect, the more diversifiable and, hence, bigger the company, the more it is exposed to market shortfalls. In addition, the Solvency II framework tends towards the financialisation of insurance business. To avoid these dangers, the author believes that substantial adjustments in the Solvency II framework are necessary.

The second contribution, by Joël Wagner and Markus Kreutzer, takes us again to the new solvency regulation as provided for by Solvency II. His contribution is an analysis of the perceived magnitude of the impact, effects and uncertainty accompanying introduction of Solvency II and the Swiss Solvency Test in place since 2011.The whole analysis is based on the industry survey conducted in the summer of 2011 among the CEOs of around 70 primary insurers.

The next paper of this special volume, by Dirk Höring, concentrates its attention on the potential impact of Solvency II on insurers' asset allocation. To this end, the author takes a simple but well-justified approach. He studies the extent to which the future capital requirements for market risk provided for by the Solvency II standard model deviate in their impact from those of Standard \& Poors' current rating model. He concludes that for a comparable level of confidence, the rating model requires from the life insurers nearly 70 per cent more capital for market risk than the future Solvency II standard.

The following contribution by Jiang Cheng and Mary A. Weiss presents the results of an empirical investigation of the relationship between capital and risk in U.S. property-liability insurance from 1993 to 2007. The period selected allows for 
comparisons of insurer's behaviour in the time prior to the introduction of the riskbased capital (RBC) system into the U.S. regulatory framework in 1994 and after it was introduced. The study confirms a basically positive relationship between risk and available capital after introduction of RBC and thus underlines its modernising role. The capital measures are based on surplus, while measures of risk are based on asset and underwriting risk.

Caroline Siegel addresses the very timely issue of solvency assessment for the needs of insurance groups and financial conglomerates. She sees its relevance in the context of regulatory requirements but, in fact, its roots are probably elsewhere - in the need for rational capital allocation from the perspective of the groups themselves. The paper compares three currently existing approaches - the NAIC (National Association of Insurance Commissioners) solo method in the U.S., the Swiss Solvency Test group structure model and the Solvency II Directive on solvency assessment with the five different criteria provided for in the IAIS draft paper on supervision of internationally active insurance groups. The analysis concludes that it is the best performing of the three approaches.

In the next contribution, Karsten Paetzmann and Christine Lippl draw our attention to the specificity of the accounting for European insurance M\&A transactions. Its practical importance cannot be contested in view of the coming wave of mergers and acquisitions that usually follow bust periods in market developments. The authors compare fair value as required for purchase accounting within the current International Financial Reporting Standards Phase II (IFRS 4 Phase II) process, the proposed Solvency II regulation and the practical actuarial concept of market-consistent embedded value. The purpose of their analytical effort is to identify and analyse key questions with respect to fair value of insurance in an M\&A transaction context.

Martin Eling and Stefan Holder focus their attention on life insurance and the challenge of the maximum technical interest rate in life insurance contracts. The paper compares regulatory frameworks in this regard in four European countries-Austria, Germany, Switzerland and the U.K. as well as the United States. In the first three countries, the maximum rate is set by a long-term rolling average of government bond yields and is adjusted by regulators. In contrast, corporate bonds are used in the U.S. and regulators are not directly involved in setting maximum ceilings. In the U.K., the technical interest rate is based on a company-specific-principle method. The paper does not intend to favour any approach but rather to take stock of the existing solutions that regulators might consider in their decision-making process.

In the last contribution of this special issue, Tristan Nguyen and Philipp Molinari take up the complex issue of the accounting valuation of insurance liabilities. They attempt in their paper to critically analyse the new rules presented in the IASB Exposure Draft "Insurance Contracts" and to discuss its recommendations. In addition, the authors assess the feasibility of implementing new rules and possible problems faced by the insurance industry when adjusting to relevant processes and systems. The authors conclude that, with the IASB Exposure Draft, the former strict market orientation has been abandoned in favour of the valuation process completely. It recommends new valuation principles independent of synthetic construction of market pricing and avoiding the kinds of distortion that result from overall market failure. 
In conclusion, this issue offers an interesting and diversified palette of contributions that closely echo current international regulatory debates. It also presents a variety of views and novel methodological approaches, as well as interesting new perspectives.

\section{References}

Accenture (2010) 'Most European Insurers Say Compliance with Solvency II Will Cost More than Originally

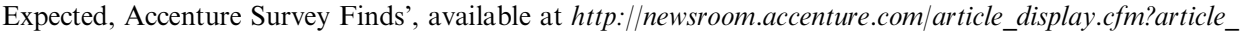
$i d=5105$, accessed 7 February 2013.

Avgouleas, E. (2012) Governance of Global Financial Markets: The Law, The Economics, The Politics, Cambridge: Cambridge University Press.

Brown, E.F. (2009) 'The development of international norms for insurance regulation', Brooklyn Journal of International Law 34(3): 954-972.

Carney, M. (2012) Letter to G20 Finance Ministers and Central Bank Governors-Progress of Financial Regulatory Reforms, Financial Stability Board (FSB), 31 October.

Haldane, A. (2012) The Dog and the Frisbee, Paper presented at the Federal Reserve Bank of Kansas City's 36th economic policy symposium "The Changing Policy Landscape", Jackson Hole, Wyoming, 31 August.

IAIS (2012a) Insurance Core Principles, Standards, Guidance and Assessment Methodology, 1 October 2011, amended 12 October 2012, pp. 14-15, available at http://www.iaisweb.org/Insurance-Core-Principlesmaterial-adopted-in-2011-795.

IAIS (2012b) Common Framework for the Supervision of Internationally Active Insurance Groups, Draft, 6 June, available at http://www.iaisweb.org/Common-Framework-765.

Posner, R.A. (1974) Theories of economic regulation, NBER Working Paper Series, Working Paper No. 41, May. 